\title{
La validez de los conocimientos otros para Bacon: griegos y romanos de la Antigüedad y los autóctonos americanos
}

\section{The validity of the other knowledge for Bacon: Greeks and Romans of antiquity and the Native Americans}

\author{
Diana Solano Villarreal \\ Escuela de Filosofía \\ Universidad Nacional, Costa Rica \\ 1.solano.villarreal@una.cr \\ .. pues la verdad del ser y la verdad del saber \\ son una misma, y no difieren entre sí más \\ que el rayo directo del rayo reflejado.
}

Francis Bacon

\begin{abstract}
Resumen
Este artículo versa sobre la visión de Francis Bacon en lo que respecta a la validez de los conocimientos otros, el caso de los griegos y los romanos en la Antigüedad y de los autóctonos americanos para el siglo XVI. Se pretende analizar la validez que para Bacon tendrían los conocimientos producidos por los griegos, romanos y las culturas autóctonas americanas y su relación con el dominio en nuestros días, en las obras El Avance del Aprendizaje, Preparación hacia una Historia Natural y Experimental, Valerius Terminus: o de la Interpretación de la Naturaleza y Dignitate et Augmentis Scientiarum, desde las teorías del grupo modernidad/colonialidad y la modernidad bipolar, en los estudios decoloniales.
\end{abstract}

Palabras claves: conocimiento, dominio, autóctonos americanos, Francis Bacon 


\begin{abstract}
This article is about the vision of Francis Bacon regarding the validity of other knowledge, the case of the Greeks and Romans in Antiquity and Native Americans for the 16th century. It is intended to analyze the validity that for F. Bacon would have the knowledge produced by the Greeks, Romans and Native American cultures and its relationship with the domain in our days, in his works The Advancement of Learning, Preparation for a Natural and Experimental History, Valerius terminus: or the interpretation of nature and Dignitate et Augmentis Scientiarum from the theory of the group modernity/ coloniality in the decolonial studies of colonial.
\end{abstract}

Keywords: knowledge, dominion, American authochthonics, Francis Bacon

\section{Introducción}

D urante la Modernidad, en el polo metropolitano caracterizado por la producción del conocimiento, dominio de la naturaleza y liberación, esta que al igual que las otras dos (conocimiento y dominio) casi nunca ha sido íntegra, incluso en la cuna de la Modernidad, de la Modernidad metropolitana, la liberación nunca alcanzó su punto máximo, o sea, la liberación de todos los seres humanos. Siempre en la Modernidad, desde sus inicios, ha existido un componente de dominio de unos seres humanos sobre otros. Dado que Bacon propone la liberación de los seres humanos, mediante la emancipación de los "Ídolos de la mente" como condición previa para transitar el camino hacia la verdad, y sabemos que Bacon deja claro que no todas las personas están en condiciones de poder romper las cadenas de los "Ídolos de la mente", creemos que quizás en los planteamientos liberadores del filósofo inglés encontremos algunos de los casos donde la liberación planteada es sólo parcial.
Releer a autores como Bacon desde un nuevo punto de vista es sumamente importante en tanto debe tenerse muy en cuenta:

en la tradición intelectual en la cual se insertan y ayudan a delinear. Más en concreto, en su posible influencia en la creación y reforzamiento del polo colonial de la modernidad, al interior del cual actúan como signos concretos de un discurso mayor, el occidentalista occidentocéntrico. Así entendidos los significados de los textos no derivan sólo en lo que dicen, sino también en lo que no dicen, y más aún de las repercusiones que lo que dicen y lo que no dicen obtienen al ser considerados en sus interrelaciones con otros autores y textos de la misma tradición. Interesa, entonces, un campo de fuerzas, una tradición intelectual que no está completa. (Herrera, 2005, p.20)

En este sentido, nos centraremos no tanto en lo que Bacon pudo decir, como en lo que dejó de decir. 


\section{Griegos y romanos}

Para los estudiosos de Bacon, sean legos o avanzados, así como para los estudiosos de la filosofía y algo del público general anglosajón, la postura del mencionado filósofo inglés respecto al conocimiento de los griegos y romanos es bien conocida. En cuanto a los conocimientos creados y desarrollados en la Antigüedad por los filósofos griegos y romanos la cuestión es cerrada, estaban equivocados. Su sistema epistemológico era muy limitado $\mathrm{y}$, por tanto, su conocimiento era inservible.

Ahora bien, de toda la filosofía de los griegos y de las ciencias particulares que derivaron de ella, a duras penas se puede, después de un lapso de tantos años, aducir un solo experimento realmente aceptable que haya contribuido a aliviar y mejorar el estado del hombre, o que pueda aprovecharse para las especulaciones y dogmas de la filosofía [...] por lo cual, del mismo modo que en religión se nos previene y se nos recomienda que nuestra fe se eche a ver en nuestras obras, así puede aplicarse esto muy oportunamente a la filosofía juzgándola por sus frutos y dando por vana aquella que sea estéril: muy especialmente en el caso de que, en lugar de frutos de vid y de oliva, produzca cardos y espinas de disputas y contiendas. (Bacon, 1991, p. XXIII)

Esteril en tanto pudiera utilizarse para mejorar o hacer más simple la vida diaria, no en tanto especulación pues a este respecto se llegó muy alto y aunque Bacon entendía el valor y la importancia de este tipo conocimiento, consideraba una parte (y no la totalidad) poco útil más allá de ciertas esferas puramente metafísicas. Es sólo que consideraba que el conocimiento no podía quedarse allí, debía trascender a las esferas prácticas, o lo que él entendía por práctico pues toda la teoría ético-política de Platón ni se creó a partir de la mera especulación, ni se esperaba que se quedara en ella (en la mera especulación). Platón recorrió muchas ciudades de la Helade (algunos especulan que pudo haber llegado hasta Egipto) para recopilar suficiente información que le ayudara con su propuesta política, la cual siempre tuvo miras y el mismo Platón intentó llevar a la práctica.

En todo caso, se comprende que Bacon no entendiera adecuadamente o no conociera a Platón como lo hacemos hoy. Los neoplatonismos se consideraron platonismo por muchos siglos y de cierto que no se contaba con todos los textos de Platón y no habían pasado por el (a veces traumático, tal como lo fue en el siglo XIX) proceso de crítica, selección y discriminación de los textos originales, apócrifos y dudosos del filósofo ateniense.

Lo mismo sucedió con el estagirita. Harto conocida es la crítica lapidaria que Bacon dirige a la filosofía de Aristóteles o más propiamente al aristotelismo medieval. Decimos lo anterior pues muchas de las acusaciones de Bacon, especialmente hacia la propuesta epistémica del estagirita, están contaminadas con prejuicios que bien se pueden rastrear hasta los aristotelismos antiguos y se desarrollaron ampliamente durante la Edad Media. No obstante, Bacon creía que los griegos y los romanos tenían episteme, limitada, con resultados cuestionables, pero la tenían. 
Lo más interesante para los efectos de este trabajo es el hecho de que los llamados posteriormente griegos, aunque considerados cuna de la civilización occidental, en la antigüedad exibían muchas características de los pueblos orientales $\mathrm{y}$, no es casualidad, su cercanía geográfica con lo que hoy conocemos como Oriente ejercía necesariamente una gran influencia sobre los helenos.

Para tiempos de Bacon, la gran influencia de los helenos sobre Europa era un hecho aceptado y bien conocido por todos los intelectuales de la época. La filosofía helena, no el pueblo como tal, pues no será hasta la mitad del siglo XIX cuando Grecia se constituya como un pueblo aparte y no como parte del Imperio Turco- Otomano, imperio eminentemente oriental. Al final, bien podría ser que las bases mismas (especialmente las epistémicas) de la tan jactanciosa cultura occidental estén en Oriente.

\section{La episteme fuera de Europa}

En cambio, los persas, árabes (quienes fueran el faro del conocimiento mundial en el Viejo Mundo ${ }^{1}$ durante toda la Edad Media), africanos y americanos ni siquiera son mencionados, es decir, para Bacon no existe episteme en sus culturas. Lo anterior podría parecer baladí, pero no lo es. Bacon ha sido para la construcción de la modernidad un pilar, un basamento sumamente importante. Sin tener jamás la claridad ni la brillantez de Descartes, los ingleses intentan encontrar en Francis Bacon su versión insular del filósofo de $\mathrm{La}$

1 Por Viejo Mundo entendemos las culturas que se desarrollaron en Europa, el norte de África y el Próximo y Medio Oriente.
Haye. En ese tanto, el Barón de Verulam ha sido una influencia por demás determinante para los ingleses (que así lo han querido), quienes a su vez han sido una fuerza imparable en la expansión e imposición, muchas veces de forma violenta, de los valores morales y especialmente epistémicos de la modernidad.

En este punto es necesario recordar un aspecto importante de la teoría de la Modernidad Bipolar: "es un proceso único, pero articulado alrededor de dos polos distinguibles aunque interdependientes" (Herrera, 2007, p.20). La modernidad tiene entonces, un doble conjunto de objetivos, una doble agenda, definida por la diversa articulación de los tres ejes básicos de la modernidad como proceso global: conocimiento, dominio y liberación. "Su polo metropolitano implementó una agenda que incluía algunos procesos liberadores, tan reales como parciales, basados en un conocimiento que incrementó el dominio de la realidad" (Herrera, 2007, p.22). Según la teoría de la Modernidad Bipolar, los dos polos de la modernidad son el polo periférico, formado por las colonias europeas en ultramar (siglos más adelante conocidas como ex colonias) y el polo metropolitano (Europa y posteriormente lo que se conocerá como Estados Unidos, Canadá y Australia).

La negativa de Bacon por siquiera considerar a los demás pueblos de la Tierra, especialmente a los pueblos autóctonos americanos como si fueran capaces de crear algún tipo de conocimiento válido, es rotunda. Decimos conocimiento válido en cuanto que no todo conocimiento era considerado útil e importante. Los 
conocimientos que a juicio de los conquistadores europeos, ciento cincuenta años antes que Bacon y Descartes escribieran, estuvieran fuera de su concepto de saber, serían ignorados o destruidos.

Ahora bien ¿cómo sabemos que Bacon no consideraba los conocimientos de los no europeos como tales? Las siguientes citas nos pueden aclarar la situación. En la edad posterior al diluvio, el primer gran juicio de Dios sobre la ambición del hombre fue la confusión de lenguas, con lo cual quedó gravemente impedido el libre comercio e intercambio de saber y conocimientos (El subrayado es nuestro) (Bacon, versión Kindle, p. XXX). En otro momento dice:

Y por eso vemos que en el comercio entre gentes bárbaras que no comprenden unas lenguas de las otras, y en la práctica de los mudos y sordos, se expresa lo que se piensa mediante gestos, que, aunque no perfectamente, sirven para lo que pretende. Y sabemos también que en China y los reinos del Extremo Oriente hay la costumbre de escribir en caracteres reales, que no expresan en general letras ni palabras, sino cosas o ideas, hasta el punto de que los países y provincias que no entienden unos las lenguas de los otros pueden no obstante, leer los respectivos escritos, porque el área de difusión de los caracteres es mayor que la de las lenguas; $y$ por eso tienen una enorme cantidad de caracteres, tantos supongo, como palabras radicales. (Bacon, versión Kindle, p. 2642- 2643)

El comercio entre gentes bárbaras, dice Bacon, es decir, gentes no civilizadas, gentes no europeas. En esa odiosa categoría de bárbaros encajaron de hecho a los pueblos originarios de América (y tristemente hay quienes los siguen encajando a ellos y nosotros los mestizos ${ }^{2}$ ), los otros, quienes no tienen ni la capacidad de comunicarse entre ellos si no es mediante gestos y ademanes pues no podrían aprender otra lengua fuera de la materna, no podrían aprender las lenguas europeas adecuadamente para el intercambio de saber y conocimientos. Es decir, los no europeos no estarían en capacidad ni de recibir los conocimientos que los europeos quisieran compartir ¿Cómo sabemos que Bacon consideraba a los autóctonos americanos menos inteligentes que a los europeos? Bien, en otro documento ${ }^{3}$ hemos recogido la siguiente cita de la obra El Avance del Saber: ...donde vemos que el Prometeo de las Indias Occidentales no tenía inteligencia con el europeo... (Bacon, versión Kindle, p. XXX). Por otra parte, según la explicación que se nos da en La Nueva Atlántida, los autóctonos de América sufrieron la justicia divina mediante un diluvio. Este, aunque no llegó a cubrir los picos de las más altas montañas, sino que llegó solamente a no más de cuarenta pies desde el suelo (Bacon, 1991, p. 196), duraron mucho las aguas en descender y por ello aunque murieron muchas personas y animales, se lograron salvar los pájaros y algunos salvajes habitantes de los montes escaparon (Bacon, 1991, p. 196). Los que no murieron en la inundación:

2 Mestizos en tanto nosotros latinoamericanos somos una mezcla. No solo de autóctonos americanos y europeos, sino también de africanos y posteriormente en el caso de los centroamericanos con chinos, de los peruanos con japoneses, de los mexicanos con libaneses... en fin un crisol de colores, sabores creencias, culturas en general. La riqueza que solo el sincretismo de tantas culturas pueden producir.

3 En en el artículo Sobre la negación absoluta de la Otredad en Francis Bacon, actualmente en prensa en la revista Repertorio americano. 
...perecieron por falta de alimentos y otras cosas necesarias. Por tanto, no os maravilléis de la escasa población de América ni de la rudeza e ignorancia de su gente, pues debéis considerar a los habitantes de América como un pueblo joven, mil años por lo menos más joven que el resto del mundo, pues fue el tiempo entre el diluvio universal y esta su inundación. (Bacon, 1991, p. 196) (El subrayado es nuestro).

La anterior descripción de los autóctonos americanos es evidentemente influenciada por el prejuicio. Porque si bien es cierto, la mayoría de los pobladores de lo que hoy conocemos como América del norte al momento del arribo de los españoles e ingleses (exceptuados los Aztecas), vivían en condiciones materiales modestas, ni era una población escasa, ni eran ignorantes. Conocían muchas cosas que recién ahora se están redescubriendo y entendiendo. Solamente la visión eurocentrada puede explicar que percibieran a los entonces habitantes de América como lo hicieron los europeos.

En cuanto al escaso remanente de la semilla humana que quedó en sus montañas, pobló de nuevo el país lentamente, y como era gente sencilla y salvaje - no como Noé y sus hijos, que constituían la principal familia de la tierra-no fueron capaces de dejar cartas, artes ni civilización a su posteridad... (Bacon, 1991, p. 196)

Podemos ver con gran claridad el concepto que, prácticamente a priori, tenía Bacon sobre los autóctonos americanos y no solamente sobre nosotros. La cita que dio origen a este punto lo expresa muy abiertamente: $Y$ sabemos también que en China y los reinos del Extremo Oriente hay la costumbre de escribir en caracteres reales, que no expresan en general letras ni palabras, sino cosas o ideas, hasta el punto de que los países y provincias que no entienden unos las lenguas de los otros pueden, no obstante, leer los respectivos escritos (Bacon, versión Kindle, p. 26422643). Es decir, los pueblos no europeos del mundo no tenían ni la capacidad de comunicarse. Si los autóctonos de Asia, África y América, que eran los conocidos por los europeos en ese momento, no podían comunicarse entre ellos mismos, menos podemos hablar de comunicarse con otras culturas. Aunado a lo anterior tenemos lo que hemos dicho anteriormente: Bacon consideraba a los pueblos originarios (de lo que se conocerá después como América) menos inteligentes que los europeos.

Teniendo en mente tales prejuicios, no es de extrañar que el verulano pensara que ninguna persona que no fuera europea (para empezar, pues había muchos requisitos más ${ }^{4}$ ) pudiera generar conocimiento válido. Los conocimientos otros, recién están siendo vindicados ante los ojos de los europeos, sus descendientes directos sin mezcla y ante nosotros las personas mestizas que vivimos en sus ex colonias.

No obstante, si bien el pensamiento de Francis Bacon ha influído fuertemente a la civilización occidental moderna tanto en su polo metropolitano como en su polo colonial, no podemos olvidar que como cualquier otro ser humano es sujeto histórico y como tal sus ideas no surgen de

4 Para mayor profundización sobre el tema de quiénes pueden producir conocimiento válido, ver el artículo, El Barón de Verulam y el vulgo, publicado en el número 143 de la Revista de Filosofia de la Universidad de Costa Rica. 
la nada. Bacon expresa y sistematiza los pensamientos de la sociedad, de la cultura a la cual perteneció.

En otras palabras, si bien es cierto el filósofo inglés pudo haber llevado al extremo el sentir del colectivo que lo rodeaba, también es cierto que lo justificó y en eso radica la importancia de su obra, por lo menos en lo que a fortalecer los mitos de superioridad epistémica de la cultura europea respecta.

Los conquistadores españoles habían llegado a América sesenta y nueve años antes del nacimiento del vizconde de Saint Albans y la Controversia de Valladolid había iniciado y terminado ( $\sin$ una resolución final, por cierto) también antes de su alumbramiento. Las disputas respecto a quiénes y qué eran los autóctonos americanos, los argumentos a favor y en contra de asuntos tan delicados y fundamentales como la posesión de alma y con eso el estatus de humanos, ya eran harto conocidas cuando Bacon aprendía a leer y escribir.

Es verdad que algunos filósofos escribieron y defendieron posiciones que contravenían directamente los cánones morales, políticos y económicos de su época (tal es el caso de Platón quien abiertamente consideraba a las mujeres como casi iguales a los hombres). Pero no es el caso de Bacon. No en cuanto a los menesteres que ocupan esta pequeña reflexión.

\section{EI conocimiento es poder}

El conocimiento es poder, el conocimiento es la llave para el dominio. Consignas de la modernidad que se desprenden de los escritos de Francis Bacon. Empero, tal y como lo han demostrado los estudios decoloniales, el sujeto que domina no es cualquier sujeto. Es el europeo. El objeto, todo y todos los demás.

Con el primero se pretende evitar que los espíritus vulgares tengan acceso a los secretos de los conocimientos, y reservar estos para oyentes selectos, o ingenios de agudeza bastante para el velo.

Tal y como explicamos en otro trabajo ${ }^{5}$, para Bacon son muy pocos los individuos que no pertenecen al vulgo y casi todos los que sí. Mujeres, niños, casi todos los hombres europeos y todos los no europeos en el mundo son vulgo. A todos los anteriormente mencionados se les veta la producción $\mathrm{y}$, de hecho, cualquier participación que no sea el mero disfrute (y esto con medida pues son los que producen el conocimiento quienes deciden qué se da y que no ${ }^{6}$ ) de los resultados de las investigaciones. Expresémolo en términos lógicos:

El conocimiento es poder.

Solo muy pocos tienen el conocimiento. Luego, solo unos pocos tienen poder.

He aquí la verdadera naturaleza del silogismo del saber-poder. Si el conocimiento es poder y ese conocimiento se encuentra en muy pocas manos, todos los demás serán despojados del poder y por ello se convertirán tarde o temprano en objetos del poder, es decir, en dominados.

Ahora bien, según el barón de Verulam, no todos los dominios tienen el mismo mérito,

5 El barón de Verulam y el vulgo. Revista de Filosofia UCR, Número 143.

6 Para más información se puede revisar el texto de Francis Bacon, La Nueva Atlántida. 
o en palabras textuales, la misma dignidad. Los dominios tienen jerarquía. En el Avance del conocimiento se lee a la letra:

...pasemos al tema del poder y el mando, y pensemos si, rectamente considerado, lo hay que se pueda comparar con aquel con que el conocimiento inviste y corona la naturaleza humana. Vemos que la dignidad del dominio es conforme a la dignidad de lo dominado: tener dominio sobre bestias, como tienen los pastores, es cosa desdeñable; tenerlo sobre niños, como tienen los maestros, es cosa de poco lustre $^{7}$; tenerlo sobre galeotes es más oprobio que honor. Ni es mucho mejor el dominio de los tiranos, sobre gentes que han renunciado a la grandeza de ánimo... Sin embargo, el dominio que otorga el conocimiento es aún más alto.

En pocas palabras, solo los que tengan acceso al dominio del saber tendrán verdadero mérito o dignidad. Todos los demás tipos de dominio carecerán de verdadero dominio o poder. La cita continúa: ... "'que el dominio sobre la voluntad: porque es un dominio sobre la razón, la fe y el entendimiento del hombre. Que son la parte más importante del espíritu, y que a la propia voluntad dan ley." Así las cosas, los demás individuos nunca tendrán por sí mismos, desde sí mismos, control de su voluntad ni ley. Es a quienes tienen el poder del conocimiento a quienes les corresponderá imponer la ley a los demás.

\section{Conclusión}

Desde el siglo XVI, la Modernidad ha declamado a todos los pueblos de la Tierra

7 En la época de Francis Bacon, en Inglaterra, el castigo físico hacia los niños para disciplinarlos era no solo aceptado, sino obligado. que ella nos ha traído la luz de la razón y la democratización del conocimiento, pero ahora sabemos que tal cosa no es más que un mito. Un mito que millones de seres humanos han tenido, y siguen teniendo, como una de las verdades más grandes jamás develadas. Se compara el conocimiento moderno con la Antigüedad helena, romana, del Medio Oriente y Egipto, calificándola no solo como relativamente válida, sino por naturaleza oculta, toda vez que se reservó para élites tales como gobernantes, sacerdotes y algunos aristócratas. En contraposición, el saber de la modernidad es completo, absoluto y únicamente válido. Es el CONOCIMIENTO. universal pues se puede aplicar para todos los seres vivientes y los que no lo son, y trascendental en cuanto funcional para todo tiempo y espacio.

El conocimiento, el poder y el dominio que derivan de estos nunca fue pensado por Bacon, uno de los pilares de la modernidad, para todos. Es verdad que la información, especialmente en los últimos veinte años, ha llegado a donde nunca se pensó que pudiera llegar, para bien y para mal. Información, no conocimiento, pues son conceptos diferentes, relacionados sí, pero no sinónimos.

La información puede ser errónea, falsa y muy manipulable (cosa que se ha hecho desde siempre); basta con recordar los enormes malentendidos (por decir lo menos) que ha traído la mala traducción intencionada de la Biblia, a la conciencia y el accionar de los individuos y colectivos occidentales y occidentalizados. Durante siglos se adoctrinó a los autóctonos americanos, a su descendencia directa y a 
los mestizos con lo que se quiso revelar de la Biblia, con las consecuencias que podemos ver hasta hoy día.

Para la modernidad ningún otro tipo de pensamiento o conocimiento es tal. Bacon es la mejor muestra de esto. Si ni los helenos, romanos, egipcios, autóctonos americanos, africanos, árabes, habitantes del Medio y Lejano Oriente (para utilizar sus propios términos) y africanos, produjeron jamás mayores ${ }^{8}$ conocimientos válidos, la Antigüedad se percibió y se sigue percibiendo por demasiadas personas como una prolongada (y a la larga como innecesaría) etapa en el camino a la ciencia moderna.

Lo más interesante es que el conocimiento científico no es ni nunca ha sido (cosa que recién comenzamos a entender) el único y verdadero (consigna utilizada durante milenios por la Iglesia Católica Romana). Todos los pueblos han producido y siguen produciendo saber. El gran problema es que en gran parte de la conciencia colectiva occidental y occidentalizada, se mantiene vivo el mito moderno del conocimiento. En nosotros los que sabemos, recae el deber moral y epistémico de desmantelar esta gran mentira y vindicar la sabiduría de todos los pueblos de la Tierra.

8 Decimos mayores pues Bacon consideraba a gran parte de la filosofía helena, no solo importante, sino también irrenunciable para producir ciencia en el sentido moderno del concepto. Este tema será desarrollado en un próximo trabajo.

\section{Referencias}

Bacon, F. (2009). Novum Organon. Madrid: Trotta.

Cajigas-rotundo, J. (2007). "La biocolonialidad del poder. Amazonía, biodiversidad y ecocapitalismo". En Santiago Castro-Gómez y Ramón Grosfoguel (comps.). El giro decolonial. Reflexiones para una diversidad epistémica más allá del capitalismo global. Bogotá: Universidad Javeriana-Instituto Pensar, Universidad Central-IESCO, Siglo del Hombre Editores.

Castro-Gómez, S. (1996). Crítica de la razón latinoamericana. Barcelona: Puvill Libros.

Castro-Gómez, S. (2005). La hybris del punto cero. Ciencia, raza e Ilustración en la Nueva Granada 17501816. Bogotá: Universidad Javeriana-Instituto Pensar.

Castro-Gómez, S. (2005). "Ciencias sociales, violencia epistémica y el problema de la "invención del otro". En Edgardo Lander (comp.). La colonialidad del saber: eurocentrismo y ciencias sociales. Perspectivas Latinoamericanas. Buenos Aires: Clacso.

Castro-Gómez, Santiago (ed.). (2000). La reestructuración de las ciencias sociales en América Latina. Bogotá: Instituto Pensar.

Castro-Gómez, S., Guardiola-Rivera, O. y Millán de Benavides, C. (eds.). (1999). Pensar (en) los intersticios. Teoría y práctica de la crítica poscolonial. Bogotá: Instituto Pensar. 
De las Casas, B. En http:www.ordiecole. com/las_casas_destruccion.pdf

Descartes, R. (1986). Discurso del método. Madrid: Alianza Editorial.

Dussel, E. (1983). Introducción a la filosofía de la liberación. Bogotá: Editorial nueva América.

Dussel, E. (1992). "Del descubrimiento al desencubrimiento". En: Nuestra América frente al V centenario. Bogotá: Editorial El Búho.

Dussel, E. (2005). "Europa, modernidad y eurocentrismo". En Edgardo Lander (comp.). La colonialidad del saber: eurocentrismo y ciencias sociales. Perspectivas Latinoamericanas. Buenos Aires: CLACSO.

Dussel, E. (1992). 1492. El encubrimiento del otro. Hacia el origen del mito de la modernidad. Madrid: Nueva Utopía.

Dussel, E. (1998). Ética de la liberación en la edad de la globalización y de la exclusión. Madrid: Trotta.

Dussel, E. (2007). Política de la liberación. Historia mundial y crítica. Madrid: Trotta.

Escobar, A. (2005). Más allá del Tercer Mundo: Globalización y Diferencia. Bogotá: ICANH.

Escobar, A. Mundos y conocimientos de otro modo. En: http://www.decoloniality. net/files/escobar-tabula-rasa.pdf

Fanon, F. (2003). Los condenados de la tierra. Prefacio de Jean-Paul Sartre. Epílogo de Gérard Chaliand. México: Fondo de Cultura Económica.

Farrington, B. (2000). Francis Bacon, Filósofo de la Revolución Industrial. Madrid: ENDYMION.
Foucault, M. (2000). La verdad y las formas jurídicas. Barcelona: Gedisa.

Foucault, M. (1987). Vigilar y castigar. Madrid: Alianza Editorial.

Galilei, G. (1891). El ensayador. Buenos Aires: Aguilar

Galeano, E. (1992). Ser como ellos y otros artículos. Buenos Aires: Siglo XXI.

Garcés, F. (2007). "Las políticas del conocimiento y la colonialidad lingüística y epistémica”. En Santiago Castro-Gómez y Ramón Grosfoguel (comps.). El giro decolonial. Reflexiones para una diversidad epistémica más allá del capitalismo global. Bogotá: Universidad Javeriana-Instituto Pensar, Universidad Central-IESCO, Siglo del Hombre Editores.

Grosfoguel, R. (2007). “Decolonizando los universalismos occidentales: el pluriversalismo transmoderno decolonial desde Aimé Césaire hasta los Zapatistas". En Santiago Castro-Gómez y Ramón Grosfoguel (comps.). El giro decolonial. Reflexiones para una diversidad epistémica más allá del capitalismo global. Bogotá: Universidad Javeriana-Instituto Pensar, Universidad Central-IESCO, Siglo del Hombre Editores.

Habermas, J. (1986). La modernidad un proyecto incompleto. En VVAA, La posmodernidad. Barcelona, Kairós.

Herrera, B. (2007). Las dos caras de la moneda: modernidad colonial y metropolitana. En: Pasos. San José, DEI.

Hernández, A. Descartes: El discurso del método. Googlebooks.

Heller, A. (1999). Una filosofía de la historia en fragmentos. Barcelona: Gedisa. 
Husserl, E. (1991). La crisis de la ciencias europeas y la fenomenología trascendental. Barcelona: Editorial Crítica.

Kamen,H. (1999). La inquisición española. Una revisión histórica. Barcelona: Crítica.

Lander, E. (ed.) (2000). La colonialidad del saber. Eurocentrismo y ciencias sociales. Perspectivas latinoamericanas. Buenos Aires: CLACSO.

Libro de las puertas. En: http://www.egiptología.org/textos/puertas/

Manzo, S. (2008). Los usos políticos del cuerpo: los dos cuerpos del Rey en la filosofía de Francis Bacon En: http://www.scielo.br/pdf/kr/ v49n117/a1149117.pdf

Mignolo, Walter (ed.) (2001). Capitalismo y geopolítica del conocimiento. El eurocentrismo y la filosofía de la liberación en el debate internacional contemporáneo. Buenos Aires: Ediciones del Signo.

Maldonado-Torres, N. (2007). "Sobre la colonialidad del ser: contribuciones al desarrollo de un concepto". En Santiago Castro-Gómez y Ramón Grosfoguel (comps.). El giro decolonial. Reflexiones para una diversidad epistémica más allá del capitalismo global. Bogotá: Universidad Javeriana-Instituto Pensar, Universidad Central-IESCO, Siglo del Hombre Editores.

Mignolo, D. W. (2002). “Colonialidad global, capitalismo y hegemonía epistémica", en Santiago CastroGómez, Freya Schiwy y Catherine Walsh, (comps). Indisciplinar las ciencias sociales. Geopolítica del conocimiento y colonialidad del poder. Perspectivas de lo andino.
Mignolo, D. W. (2002). Historias locales/ diseños globales. Colonialidad, conocimientos subalternos y pensamiento fronterizo. (Prefacio). México: Akal Ediciones.

Mignolo, D. W. (2005). "La colonialidad a lo largo y a lo ancho: el hemisferio occidental en el horizonte colonial de la modernidad". En Edgardo Lander (comp.). La colonialidad del saber: eurocentrismo y ciencias sociales. Perspectivas Latinoamericanas. Buenos Aires: CLACSO.

Mignolo, D. W. (2007). "El pensamiento decolonial: desprendimiento y apertura”. En Santiago Castro-Gómez y Ramón Grosfoguel (comps.). El giro decolonial. Reflexiones para una diversidad epistémica más allá del capitalismo global. Bogotá: Universidad Javeriana-Instituto Pensar, Universidad Central-IESCO, Siglo del Hombre Editores.

Quijano, A. (2007). "Colonialidad del poder y clasificación social". En Santiago Castro-Gómez y Ramón Grosfoguel (comps.). El giro decolonial. Reflexiones para una diversidad epistémica más allá del capitalismo global. Bogotá: Universidad Javeriana-Instituto Pensar, Universidad CentralIESCO, Siglo del Hombre Editores.

Negri, A. (2008). Descartes Político. Madrid: Ediciones Akal.

Negri, A. (2008). Descartes político. En: http://books.gloogle.es/books?i $\mathrm{d}=\mathrm{af} 82 \mathrm{t} 651 \mathrm{VSqUC} \&$ printse $=\mathrm{fr}$ ontcover\&dq=intitle:descartes+ intitle:político/inauthor:antonio/ inauthor:negri 
O’Gorman, E. (2002). La invención de América. México: Fondo de Cultura Económica.

Pachón, D. (2006). Filosofía vitalista y economía solidaria. Bogotá: Produmedios.

Peltonen, M. (ed.) (1996). "Bacon's political philosophy" en: The Cambridge Companion to Francis Bacon. http://books.google.com/books/ about/The_Cambridge_Companion_to_Bacon.html?id=aXyc_ VCh4y0C\&redir_esc=y

Quijano,A.(2005). “Colonialidad del poder, eurocentrismo y América Latina”. En Edgardo Lander (comp.). La colonialidad del saber: eurocentrismo y ciencias sociales. Perspectivas Latinoamericanas. Buenos Aires: CLACSO.

Quijano, A. (1998). "Colonialidad, Poder, Cultura y Conocimiento en América Latina”. Anuario Mariateguiano, vol. IX, No. 9, pp.113-122. Lima.

Quijano, A. (1992). "Colonialidad y Modernidad/Racionalidad". En: Heraclio Bonilla (comp.): Los Conquistados. 1492 y la población indígena de las Américas. Bogotá: FLACSOTercer Mundo.

Quijano, A. (1989). Modernidad, Identidad y Utopía en América Latina. Quito: Ediciones El Conejo.

Restrepo, E. (2007). “Antropología y colonialidad”. En Santiago Castro-Gómez y Ramón Grosfoguel (comps.). El giro decolonial. Reflexiones para una diversidad epistémica más allá del capitalismo global. Bogotá: Universidad Javeriana-Instituto Pensar, Universidad Central-IESCO, Siglo del Hombre Editores.
Sepúlveda, G. (1951). Demócrates segundo o de las justas causas de la guerra contra los indios. (A. Losada, Ed.). Madrid: Consejo Superior de Investigaciones científicas Instituto Francisco de Vitoria. En: www.books.google.com/ Juan_Ginés_de_Sepúlveda

Sepúlveda, G. (1987). Tratado sobre las justas causas de la guerra contra los indios. México: Fondo de Cultura Económica.

Todorov, T. (1987). La Conquista de América. El problema del otro. México, Ed. Siglo XXI.

Walsh, C. (2007). "Interculturalidad y colonialidad del poder. Un pensamiento y posicionamiento 'otro' desde la diferencia colonial". En Santiago Castro-Gómez y Ramón Grosfoguel (comps.). El giro decolonial. Reflexiones para una diversidad epistémica más allá del capitalismo global. Bogotá: Universidad Javeriana-Instituto Pensar, Universidad CentralIESCO, Siglo del Hombre Editores.

Weber, M. (1997). La ética protestante y el espíritu del capitalismo. Barcelona: Editorial Península. 